\title{
Environmental Stability of MXenes as Energy Storage Materials
}

\author{
Xinliang Li, Zhaodong Huang and Chunyi Zhi* \\ Department of Materials Science and Engineering, City University of Hong Kong, Kowloon, Hong Kong
}

In the past decade, MXenes family have undergone considerable development and have been widely investigated in various research fields, relying on their excellent physicochemical properties. Benefiting from the increasingly versatile preparation methods and the continued discovery of new members, their large-scale application has already been underway, with energy storage fields including supercapacitors and batteries leading. The synthesis methods and processing environment of MXenes, which are closely strictly to the microstructure, surface chemistry, and electronic properties, have attracted great attention. In this review, we review the phylogeny of MXenes materials in recent years, mainly focusing on the synthesis process and environmental stability.

Keywords: MXene, environmental stability, energy storage material, electrode, oxidation

\section{OPEN ACCESS INTRODUCTION}

Edited by:

Dingshan Yu,

Sun Yat-sen University, China

Reviewed by:

Yang Huang,

Shenzhen University, China

Renzhi Ma

National Institute for Materials

Science, Japan

*Correspondence:

Chunyi Zhi

cy.zhi@cityu.edu.hk

Specialty section:

This article was submitted to

Energy Materials,

a section of the journal

Frontiers in Materials

Received: 27 August 2019 Accepted: 20 November 2019 Published: 11 December 2019

Citation:

Li X, Huang Z and Zhi C (2019) Environmental Stability of MXenes as Energy Storage Materials

Front. Mater. 6:312.

doi: 10.3389/fmats.2019.00312
The term MXenes with a formula of $M_{n+1} X_{n}$, named after other $2 \mathrm{D}$ analog materials silicene, graphene, phosphorene, and so on, are synthesized by extracting A atomic layer from ternary $\operatorname{MAX}\left(M_{n+1} A_{n}\right)$ ceramics, where $M=$ early transition metal elements (Ti, $\mathrm{Zr}, \mathrm{Mo}, \mathrm{Nb}, \mathrm{V}, \mathrm{Mn}$, $\mathrm{Sc}, \mathrm{Hf}, \mathrm{W}$, and so on), $\mathrm{A}=$ group 13 or 14 ( $\mathrm{Si}, \mathrm{Al}, \mathrm{Ga}$, and so on), $\mathrm{X}=\mathrm{C}$ or/and $\mathrm{N}$ (Anasori et al., 2015, 2017). In 2011, Yury's group firstly reported the first MXene material, this is, $\mathrm{Ti}_{3} \mathrm{C}_{2}$ using $\mathrm{HF}$ solution as the etchant and $\mathrm{Ti}_{3} \mathrm{AlC}_{2}$ as the MAX precursor (Naguib et al., 2011). $\mathrm{Ti}_{3} \mathrm{C}_{2}$ is generally written as $\mathrm{Ti}_{3} \mathrm{C}_{2} \mathrm{~T}_{\mathrm{X}}$, where $\mathrm{T}_{\mathrm{X}}$ stands for the inevitable surface functional groups, such as $=\mathrm{O}$, $-\mathrm{OH},-\mathrm{F}$, considering its surface chemical properties (Lukatskaya et al., 2013). Subsequently, a series of different MXenes materials, which possesses various $\mathrm{M}$ or/and $\mathrm{C}$ or/and $n$, are synthesized and reported using similar wet chemical etching method, and the naming rules follow the convention described above. For example, $\mathrm{Zr}_{3} \mathrm{C}_{2} \mathrm{~T}_{\mathrm{X}}, \mathrm{Ti}_{4} \mathrm{~N}_{3} \mathrm{~T}_{\mathrm{X}}, \mathrm{V}_{4} \mathrm{C}_{3} \mathrm{~T}_{\mathrm{X}}, \mathrm{Ta}_{4} \mathrm{C}_{3} \mathrm{~T}_{\mathrm{X}}, \mathrm{Ti}_{2} \mathrm{CT}_{\mathrm{X}}, \mathrm{V}_{2} \mathrm{CT}_{\mathrm{X}}, \mathrm{Nb}_{4} \mathrm{C}_{3} \mathrm{~T}_{\mathrm{X}}$, $\mathrm{Cr}_{2} \mathrm{CT}_{\mathrm{X}}$ (Naguib et al., 2013; Ghidiu et al., 2014b; Urbankowski et al., 2016; Yang et al., 2016; Zhou et al., 2016; Tran et al., 2018; Wu et al., 2018; Xu et al., 2019). In the early stage, MXenes family were roughly classified into the following three categories according to the variable $n$ : $\mathrm{M}_{4} \mathrm{X}_{3}, \mathrm{M}_{3} \mathrm{X}_{2}$, and $\mathrm{M}_{2} \mathrm{X}$ (Khazaei et al., 2018). Notable, as the new synthesis methods adopted, recently, the binary transition metal MXenes equipped with different $M_{1}, M_{2}$ or $X_{1}, X_{2}$ elements instead of traditional single $M$ or $X$ layer, emerge, thus this discovery dramatically expands the range of MXenes family members and arouses ever-growing attention (Anasori et al., 2015, 2016; Fashandi et al., 2017). Their formula can be expressed as $\mathrm{M}_{1} \mathrm{M}_{2} \mathrm{X}$ and $\mathrm{MX}_{1} \mathrm{X}_{2} . \mathrm{Mo}_{2} \mathrm{TiC}_{2} \mathrm{~T}_{\mathrm{X}}$ and $\mathrm{Ti}_{3} \mathrm{CNT}_{\mathrm{X}}$ should be two good examples. At the same time, etching methods have also made significant progress. For the purpose of avoiding the usage of dangerous HF, alkali solution etching, such as $\mathrm{NaOH}$ (hydrothermal condition), $\mathrm{NH}_{4} \mathrm{HF}_{2}$, molten salts etching, such as $\mathrm{LiF}+\mathrm{NaF}+\mathrm{KF}$, and especially electrochemical etching were developed one after another (Ghidiu et al., 2014a; Urbankowski et al., 2016; Wang X. et al., 2017; Li T. et al., 2018; Yang S. et al., 2018; Li M. et al., 2019). The optimized safe processes significantly facilitate the large-scale preparation and application of MXenes family. 
In the past decade, on account of the unique intrinsic physical/chemical properties, which include high conductivity, localized layered structure, hydrophilicity, abundant surface terminations, biocompatibility, and so on, 2D MXenes materials have been thoroughly investigated. Many research works witnessed the growth and breakthrough in MXenes family. MXenes can be used in various research fields, including ceramics, conductive polymer, energy storage, sensors, water purification, catalysis, thermoelectric conversion, photothermal conversion, solar cell, biomedicine, and microwave absorption and shielding. Among them, energy storage materials are worth highlighting. Specifically, MXenes had been proven to hold ultra-high volume specific capacity as supercapacitors, exceeding $900 \mathrm{~F} \cdot \mathrm{cm}^{-3}$ (Ghidiu et al., 2014a). Their impressive talent in cation ions storage had also been confirmed by Yury and other researchers, as a series of multivalent ionic capacitors with satisfied performance including $\mathrm{Li}^{+}, \mathrm{K}^{+}, \mathrm{Na}^{+}, \mathrm{Mg}^{2+}, \mathrm{Zn}^{2+}, \mathrm{Al}^{3+}$ (Lukatskaya et al., 2013; Mashtalir et al., 2013; Er et al., 2014; Xue et al., 2017a; Kang et al., 2018; Zhu et al., 2018; Liang et al., 2019; Luo et al., 2019; Ma et al., 2019; Yang et al., 2019a; Zhao et al., 2019). For instance, $\mathrm{Ti}_{3} \mathrm{C}_{2} \mathrm{~T}_{\mathrm{X}} / \mathrm{TiO}_{2}$ enabled a capacity of $51 \mathrm{~F} \cdot \mathrm{g}^{-1}$ in the $\mathrm{KOH}$ electrolyte (Rakhi et al., 2015). What is more, by their novel microstructure and conductivity (up to 6.76 $\times 105 \mathrm{~S} \cdot \mathrm{m}^{-1}$ ), MXenes, as electrodes, both cathode, and anode, still shine brightly in the organic battery system. As to Li-S, $\mathrm{Li}^{+}, \mathrm{Al}^{3+}, \mathrm{Mg}^{2+}$, and $\mathrm{K}^{+}$batteries, MXenes sometimes showed even much better electrochemical performance than traditional carbon materials, which was quite impressive considering their much larger density (Naguib et al., 2013; Xie et al., 2014; Kim et al., 2015; Mashtalir et al., 2015; Ahmed et al., 2016; Byeon et al., 2016; Huang et al., 2016, 2017a,b, 2019; Tang et al., 2016; Dong et al., 2017; Liang et al., 2017; VahidMohammadi et al., 2017; Bao et al., 2018; Xu M. et al., 2018; Li H. et al., 2019; Liu R. et al., 2019). For example, as the cathode, about $300 \mathrm{mAh} \cdot \mathrm{g}^{-1}$ capacity could be delivered in an $\mathrm{Al} / \mathrm{Ti}_{3} \mathrm{C}_{2} \mathrm{~T}_{\mathrm{X}}$ battery, and $300 \mathrm{mAh} \mathrm{mAh} \cdot \mathrm{g}^{-1}$ was realized in an $\mathrm{Mg} / \mathrm{Ti}_{3} \mathrm{C}_{2} \mathrm{~T}_{\mathrm{X}}$ battery (VahidMohammadi et al., 2017; Xu M. et al., 2018). Similarly, as anodes, discharge capacity could be up to $1,383 \mathrm{mAh} \cdot \mathrm{g}^{-1}$ in the Li-S system based on the few-layered $\mathrm{Ti}_{3} \mathrm{C}_{2} \mathrm{~T}_{\mathrm{X}}$ (Tang et al., 2019). While being loaded other active substances, their natural layered structure coupled with much larger layer spacing than graphene could provide more space and thus superior diffusion kinetics for ions shuttle.

Up to now, more than about 30 different 2D MXenes members have been successfully synthesized, and calculations has predicted the existence of hundreds of other MXenes members due to the emergence of binary MXenes (Anasori et al., 2017). As a rising star in the energy storage field, compared to other monotonous 2D materials, MXenes with the multi-atom layered crystal structure are considered to be star materials. On the one hand, the abundant functional termination that can be adjusted by controlled etching processes, are conducive to their further chemical modification and recombination with other highly active electrode materials, which is also the focus of most researches at present (Hong $\mathrm{Ng}$ et al., 2017; Wang et al., 2018; Li M. et al., 2019; Yu et al., 2019). On the other hand, more significantly, the ordered and layered atom arrangement provides more possibilities for researchers to select suitable conditions to design MXenes derivates with the favored structure and phase composition that cannot be easily or even impossible to achieve through traditional routes.

However, in terms of MXenes themselves, natural oxidation phenomenon is an inevitable drawback for electrodes pursuing the stability during cycling (Zhang et al., 2017; Liang et al., 2018; Li H. et al., 2018; Liu et al., 2019a,b; Mo et al., 2019; Seredych et al., 2019; Yang et al., 2019b). This problem is also one of the essential reasons why MXenes-based electrodes are mainly employed in organic electrolytes, in which the absence of water or/and oxygen can effectively avoid their spontaneous oxidation. Interestingly, on the other hand, the results may be reversed if the oxidation products are electrochemically active, even higher than the parent MXenes. The oxidation process, if properly controlled, may mitigate the inevitable decline in battery capacity. In summary, the oxidation behavior of MXenes, whether passive or active, complete or incomplete, is interesting and worthy of in-depth discussion, but rarely focused on. Thus, from the perspective of bare MXenes, we summarized and analyzed the oxidation reactions of MXenes under different environmental conditions and the accompanying structure and phase composition transition.

\section{VARIOUS MXENES AND SYNTHESIS METHODS}

Etching methods have been improved over the years, from initially dangerous HF etchant to safe electrochemical etching (Anasori et al., 2015; Wang B. et al., 2017; Pang et al., 2019). The extraction of $A$ atomic layers in MAX is often accompanied by the spontaneous formation of functional groups, according to the thermodynamic calculation and experimental confirmation (Naguib et al., 2011). In this regard, different etchants used usually lead to differences in surface terminations, which should further affect the structure, electronic, and chemical properties that are strictly related to energy storage performance. Thus, in this section, we will first review and classify the reported etching methods of MXenes.

\section{WET CHEMICAL ETCHING}

HF solution as an etchant gave birth to the first MXene, $\mathrm{Ti}_{3} \mathrm{C}_{2} \mathrm{~T}_{\mathrm{X}}$, using $\mathrm{Ti}_{3} \mathrm{AlC}_{2}$ MAX ceramic as the precursor, and had been widely used to synthesize other many MXenes, such as $\mathrm{Nb}_{2} \mathrm{CT}_{\mathrm{X}}$, $\mathrm{V}_{2} \mathrm{CT}_{\mathrm{X}}, \mathrm{Ti}_{3} \mathrm{CNT}_{\mathrm{X}}$. For Al-based MAX, the proposed etching process and associated mechanism could be expressed as the following equations:

$$
\begin{gathered}
M_{n+1} A l X_{n}+H F \rightarrow M_{n+1} X_{n}+A F_{3}+1.5 H_{2} \\
M_{n+1} X_{n}+2 H_{2} O \rightarrow M_{n+1} X_{n}(O H)_{2}+H_{2} \\
M_{n+1} X_{n}+2 H F \rightarrow M_{n+1} X_{n} F_{2}+H_{2}
\end{gathered}
$$

In the beginning, as shown in Equation (1), the much weaker metallic M-A bonds compared to M-X (covalent or ionic bonds) broke first, and $\mathrm{F}$ ions then combined with the $\mathrm{Al}$ ions to form 
$\mathrm{AlF}_{3}$, with the formation and release of $\mathrm{H}_{2}$ (Naguib et al., 2011; Srivastava et al., 2016; Khazaei et al., 2018). In this way, the Al layer was pulled out of MAX bit by bit, and MXene inherited the hexagonal lattice. At this stage, MXene possessed high activity and could not be stable in water or acid, so it would spontaneous react with $\mathrm{H}_{2} \mathrm{O}$ and $\mathrm{HF}$ to reduce surface energy by generating $-\mathrm{F},=\mathrm{O}$, and $-\mathrm{OH}$ surface terminations (Figure 1A).

To avoid the direct use of toxic HF, the fluoride-contained salts combined with hydrochloric acid were developed into another capable liquid etchant, which was first proposed by Yury's group (Urbankowski et al., 2016). Many experiments showed that MXenes prepared by this modest method tended to acquire much fewer atomic defects and higher conductivity. More importantly, the fluoride salts used were available in a wide range, including $\mathrm{LiF}, \mathrm{NaF}, \mathrm{KF}, \mathrm{CaF}_{2}, \mathrm{CsF}, \mathrm{FeF}_{3}$, and so on, while the concentration of $\mathrm{HCl}$ ranged from 6 to $12 \mathrm{M}$ (Ghidiu et al., 2014a; Wang X. et al., 2017). This etchant endowed the obtained MXenes inherently capable of carrying specific ions pre-intercalation layers, resulting in large interlayer spacing that facilitated subsequent energy storage. Also, the various bifluoride-based solution, including $\mathrm{NH}_{4} \mathrm{HF}_{2}, \mathrm{NaHF}_{2}, \mathrm{KHF}_{2}$ as the etchants had been revealed in recent years (Halim et al., 2014; Feng et al., 2017). $-\mathrm{NH}_{3}$ and $-\mathrm{NH}_{4}$ could attack the $\mathrm{Al}$ layers in MAX and then inserted into interlayers of the obtained MXenes, which benefited the further delamination of MXenes. The main reaction by-products were verified to be $\left(\mathrm{NH}_{4}\right)_{3} \mathrm{AlF}_{6}, \mathrm{NH}_{4} \mathrm{AlF}_{4}$ (Halim et al., 2014). Besides, $\mathrm{NH}_{4} \mathrm{~F}$ and $\mathrm{NaOH}$ solutions came to the fore when more demanding preparation conditions were considered, such as high temperature and pressure. Liu's group successfully synthesized multi-layered $\mathrm{Ti}_{3} \mathrm{C}_{2} \mathrm{~T}_{\mathrm{X}}$ MXene by a facile hydrothermal route at $150^{\circ} \mathrm{C}$, employing $\mathrm{NH}_{4} \mathrm{~F}$ as the etching agent (Wang et al., 2016). Wei's group reported the partial etching behavior of $\mathrm{Ti}_{3} \mathrm{C}_{2} \mathrm{~T}_{\mathrm{X}}$ MXene in $1 \mathrm{M} \mathrm{H}_{2} \mathrm{SO}_{4}$ solution at $80^{\circ} \mathrm{C}$, during the hydrothermal process, after undergoing a pre-treatment of precursor $\mathrm{Ti}_{3} \mathrm{AlC}_{2}$ MAX impregnated in $1 \mathrm{M} \mathrm{NaOH}$ solution at $80^{\circ} \mathrm{C}$ for $10 \mathrm{~h}$ (Li T. et al., 2018).

\section{MOLTEN SALTS ETCHING}

Nitride MXenes reports lag far behind carbide MXenes. This is due to the difference in the chemical nature of the precursor MAX ceramics of the two, making the latter unsuitable for the mature wet chemical etching method. Their M-A bond energy can be almost the same as or slightly higher than that of the M-X bond. Consequently, the strong etchability of $\mathrm{HF}$ or other etchants may open the M-A bonds to etch away $\mathrm{Al}$ atoms, and also break M-X (N) bonds to dissolve the MXenes (Urbankowski et al., 2016). Thus, molten salts etching develops into a new method in recent years, which is mainly designed for nitride MXenes members. In 2016, Yury's group proposed the use of molten fluoride-contained salts at high-temperature etchants and successfully synthesized the first nitride MXene member, $\mathrm{Ti}_{3} \mathrm{~N}_{4} \mathrm{~T}_{\mathrm{X}}$ (Urbankowski et al., 2016). In this work, $\mathrm{Ti}_{4} \mathrm{AlN}_{3} \mathrm{MAX}$ was first mixed with the etchant $(\mathrm{NaF}+\mathrm{KF}+$ $\mathrm{LiF}$ mixture) and then sintered at $550^{\circ} \mathrm{C}$ for $30 \mathrm{~min}$ in the $\mathrm{Ar}$ flowing, followed by the removal of reaction by-products by $4 \mathrm{M} \mathrm{H}_{2} \mathrm{SO}_{4}$ solution for $1 \mathrm{~h}$. However, in terms of crystallinity, the results evidenced that the obtained few-layered $\mathrm{Ti}_{4} \mathrm{~N}_{3} \mathrm{~T}_{\mathrm{X}}$

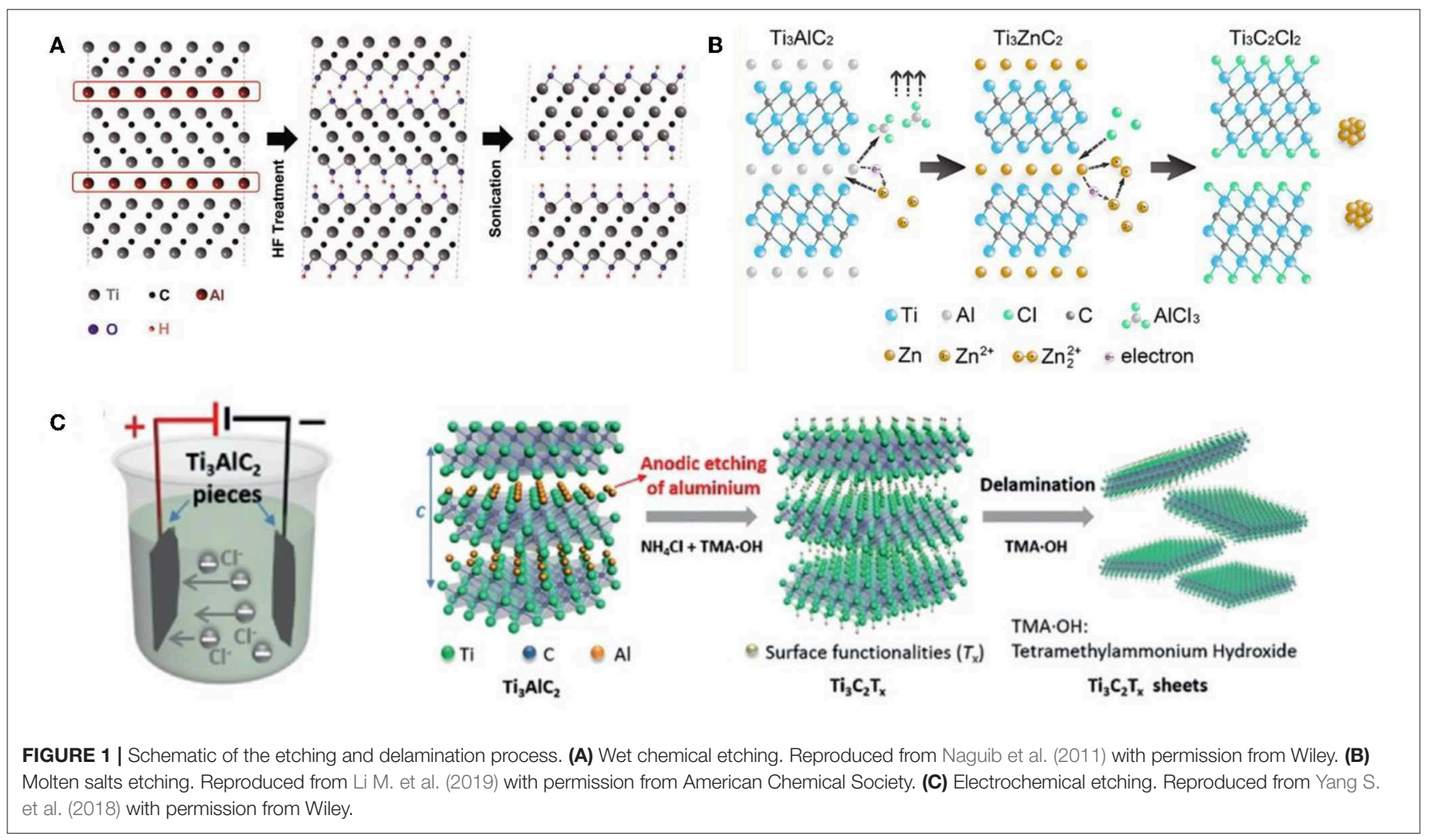


MXene exhibited more surface defects than other HF-etched counterparts. Examining the entire preparation process, this method is far more complicated than the above wet chemistry, although it is sometimes irreplaceable when taking the required high temperature, complex fluoride salts, inert atmosphere, toxic acid solution, into account.

Recent work reported by Huang's group should be highlighted, a general approach was proposed to synthesis halides-terminated MXenes by employing the Zn-based MAX as precursors and only $\mathrm{ZnCl}_{2}$ salts as the etchant (Li M. et al., 2019; Mian et al., 2019). Thus, a series of MXenes including $\mathrm{Ti}_{3} \mathrm{C}_{2} \mathrm{Cl}_{2}$ and $\mathrm{Ti}_{2} \mathrm{CCl}_{2}$, whose surfaces were terminated with only $-\mathrm{Cl}$ groups, were synthesized for the first time, after heat treatment at $550^{\circ} \mathrm{C}$ for $5 \mathrm{~h}$ in $\mathrm{Ar}$ atmosphere (Figure 1B). Remarkably, the simplified etchant, more importantly, the controllable and single functional group, takes the synthesis of MXenes to a new level. The related mechanism involved in the replacement reaction between MAX ceramics and the late transition metal halides were also clarified, as shown in the following equations:

$$
\begin{gathered}
\mathrm{Ti}_{3} \mathrm{ZnC}_{2}+\mathrm{ZnCl}_{2} \rightarrow \mathrm{Ti}_{3} \mathrm{C}_{2} \mathrm{Cl}_{2}+2 \mathrm{Zn} \\
\mathrm{Ti}_{3} \mathrm{ZnC} \mathrm{C}_{2}+\mathrm{Zn}^{2+} \rightarrow \mathrm{Ti}_{3} \mathrm{C}_{2}+2 \mathrm{Zn}^{2+} \\
\mathrm{Ti}_{3} \mathrm{C}_{2}+2 \mathrm{Cl}^{-} \rightarrow \mathrm{Ti}_{3} \mathrm{C}_{2} \mathrm{Cl}_{2}+2 e^{-} \\
2 \mathrm{Zn}^{2+}+2 e^{-}=2 \mathrm{Zn}
\end{gathered}
$$

In short, despite the considerable progress, for the moment, the intrinsic drawback described above is likely to make the molten salts etching method less accessible than the wet chemical etching.

\section{ELECTROCHEMICAL ETCHING}

MXene exfoliation can also be achieved by the electrochemical method. The selection of the electrolyte is critical, which affects not only the completeness and final yield but also the microstructure and surface chemical properties of resulted MXenes. On account of the strong interaction of halogen element $\mathrm{Cl}$ with $\mathrm{Al}$, a $\mathrm{Cl}$-contained electrolyte is a hot topic in current research (Yang S. et al., 2018; Pang et al., 2019). Feng's group adopt a binary electrolyte, this is, $1 \mathrm{M} \mathrm{NH}_{4} \mathrm{Cl}+0.2 \mathrm{M}$ TMAOH, to etch the $\mathrm{Ti}_{3} \mathrm{AlC}_{2}$ MAX to obtain the $\mathrm{Ti}_{3} \mathrm{C}_{2} \mathrm{~T}_{\mathrm{X}}$ MXene with $\mathrm{OH}$ and $=\mathrm{O}$ terminations, as shown in Figure 1C (Yang S. et al., 2018). Studies had shown that the concentration of hydroxide possessed a direct impact on the etching time and the type of final product (amorphous carbon or MXene). When the value was 0.2 , the reaction efficiency was high, and only $10 \mathrm{~h}$ was required. Besides, density-functional theory calculation revealed that the etching process occurred when $\mathrm{Ti}_{3} \mathrm{AlC}_{2}$ was positively charged as the anode. The possible equations were concluded based on the experimental results as follows:

$$
\begin{gathered}
\mathrm{Ti}_{3} \mathrm{AlC}_{2}+3 e^{-}+3 \mathrm{Cl}^{-}=\mathrm{Ti}_{3} \mathrm{C}_{2}+\mathrm{AlCl}_{3} \\
\mathrm{Ti}_{3} \mathrm{C}_{2}+2 \mathrm{OH}^{-}-2 e^{-} \rightarrow \mathrm{Ti}_{3} \mathrm{C}_{2}(\mathrm{OH})_{2} \\
\mathrm{Ti}_{3} \mathrm{C}_{2}+2 \mathrm{H}_{2} \mathrm{O} \rightarrow \mathrm{Ti}_{3} \mathrm{C}_{2}(\mathrm{OH})_{2}+\mathrm{H}_{2}
\end{gathered}
$$

When $\mathrm{Cl}^{-}$ions bonded to $\mathrm{Al}^{3+}$ and form $\mathrm{AlCl}_{3}, \mathrm{NH}^{4+}$ in the electrolyte could intercalate the existing MXene, which significantly improved the degree of completion while avoiding the possibility of etching only on the MAX surface (Lukatskaya et al., 2013; Mišković-Stanković et al., 2014). Moving forward, Hao's group improved the above technique and developed a universal thermal-assisted electrochemical etching approach (Pang et al., 2019). The safe and mild route employed pure diluted $\mathrm{HCl}$ as the electrolyte without any toxic intercalants, such as tetramethylammoniumion. The used slight heating procedure promoted the MXenes exfoliation, which had similar effects of other intercalants but completely eliminated the potential hazards. More significantly, the method had been further extended to $\mathrm{V}_{2} \mathrm{CTX}$ and $\mathrm{Cr}_{2} \mathrm{CT}_{\mathrm{X}}$ MXenes, unlike previous reports that were limited to only Ti-based MXenes, indicating iexcellent universality. Note that this technology is carried out under ambient conditions, and it can be further promised by optimizing the choice of electrolyte to avoid environmental pollution and health issues. It should be promising in terms of costs and scale in the future.

As is well-known, few-layered MXene flakes can be further obtained via the following methods. (1) Sonication; Naguib's group utilized the simple agitation and mild sonication process to delaminate multilayered MXene and obtained flexible $\mathrm{Ti}_{3} \mathrm{C}_{2} \mathrm{~T}_{\mathrm{X}}$ flakes on a large scale, as depicted in Figure 1A (Naguib et al., 2011, 2015). (2) Ions intercalation. Feng and Geng's group reported that the $\mathrm{TMA}^{+}$intercalation would lead to complete delamination of MXenes after etching. Consequently, monolayer or bilayer $\mathrm{Ti}_{3} \mathrm{C}_{2} \mathrm{~T}_{\mathrm{X}}$ flakes with hydrolyzed $\mathrm{Al}(\mathrm{OH})_{4}$ surface termination were effectively synthesized (Figure 1C) (Xuan et al., 2016; Yang S. et al., 2018).

\section{PHASE AND STRUCTURE TRANSITION UNDER DIFFERENT ENVIRONMENTAL CONDITIONS}

Excellent dispersibility enables MXenes to be stably dispersed in water, ethanol, and numerous organic solvents including acetone, ACN, DMSO, DMF, NMP, PC, giving them superior processability and chemical modification. However, MXenes are precisely a class of environmentally sensitive materials. The presence of water and oxygen causes their spontaneous phase transition coupled with microstructure changes, while light and temperature will exacerbate this degradation process. As a result, it is now common to store MXenes colloidal solution at low temperature or/and in the dark or to preserve the dried product in a vacuum or inert atmosphere to isolate moisture and oxygen, especially for few-layered MXenes. Notably, this oxidation behavior is also a direct and effective means of constructing MXene-based composites without the need to introduce any foreign objects. Their fatty elemental composition and ordered layered arrangement provide researchers unlimited operational space. Thus, in this part, we mainly focus on the response behavior and derivates of MXenes in different environments. 


\section{DEGRADATION AT ROOM TEMPERATURE}

MXenes are unstable in an open environment, even at room temperature. Yury's group took few-layered $\mathrm{Ti}_{3} \mathrm{C}_{2} \mathrm{~T}_{\mathrm{X}}$ MXenes as an example, the most studied and commonly used representative, systematically investigated and reported the oxidation behavior of its colloidal solution (Zhang et al., 2017). Results showed that the freshly prepared $\mathrm{Ti}_{3} \mathrm{C}_{2} \mathrm{~T}_{\mathrm{X}}$ MXenes colloidal solution placed in the open vial was degraded by $42 \%$ after 5 days, and ultimately degraded after 15 days (Figure 2A). The color of the solution gradually faded from black to pure white. Further XRD data confirmed that the resulting final product was $\mathrm{TiO}_{2}$ with the anatase crystal structure, after a period of $\mathrm{Ti}_{\mathrm{X}} \mathrm{C}_{\mathrm{y}} \mathrm{Ti}_{3} \mathrm{C}_{2} \mathrm{~T}_{\mathrm{X}} / \mathrm{TiO}_{2}$ composites. From the structural point of view, the oxidation phenomenon started from the edge sites of MXenes, and as time progressed, it gradually expanded toward the inside of the flakes and eventually invaded the whole. What is more, the degradation rate had a negative correction with the size of the flakes, the smaller the flakes, the faster the degradation. The proposed reaction mechanism was revealed by the following equation:

$$
\mathrm{Ti}_{3} \mathrm{C}_{2} \mathrm{O}_{2}+4 \mathrm{H}_{2} \mathrm{O}=3 \mathrm{TiO}_{2}+2 \mathrm{C}+4 \mathrm{H}_{2}
$$

Obviously, the inert carbon layer was retained after degradation. As to the few-layered $\mathrm{Ti}_{2} C T_{\mathrm{X}}$ MXene, its oxidation process and reaction product was similar to the above, only becoming more intense and rapid. Degradation occurred after a few hours and completed after only about 1 day, the color of the $\mathrm{Ti}_{2} \mathrm{CT}_{\mathrm{X}}$ colloidal solution completely turned brown to white, meaning the complete transition at this moment.

Additionally, the situation changed a lot when the sample was placed in an Ar atmosphere. After more than 3 weeks of storage, the degradation of the colloidal solutions was still very weak, and it became less obvious as the temperature decreased. In this stage, the inevitably little dissolved oxygen in the water was the main influencing factor. On the other hand, filtrating MXenes film by a simple vacuum process was very effective in retarding the degradation rate because of the shielding effect of the dense structure on the external moisture. Barsoum's group also proved the above oxidation mechanism was applicable to multilayer MXenes (Mashtalir et al., 2014). Furthermore, Alshareef's group explored the effect of oxidants on the oxidation behavior of MXenes (Ahmed et al., 2016). The following showed the possible reaction equation:

$$
a \mathrm{Ti}_{2} \mathrm{CT}_{X}+\mathrm{H}_{2} \mathrm{O}_{2} \rightarrow b \mathrm{TiO}_{2}+(1-b) \mathrm{Ti}_{2} \mathrm{CT}_{X}+\mathrm{CO}_{y}
$$

Apparently, this could be regarded as incomplete oxidation. The usage of $\mathrm{H}_{2} \mathrm{O}_{2}$ was able to accelerate the oxidation process without changing the final product significantly. By adjusting the oxidant content and reaction time, this was, the oxidation degree, the original layered structure could be selectively retained.

\section{DEGRADATION AT HIGH TEMPERATURE}

The oxidation behavior of MXenes at high-temperature conditions mainly depends on the treatment temperature
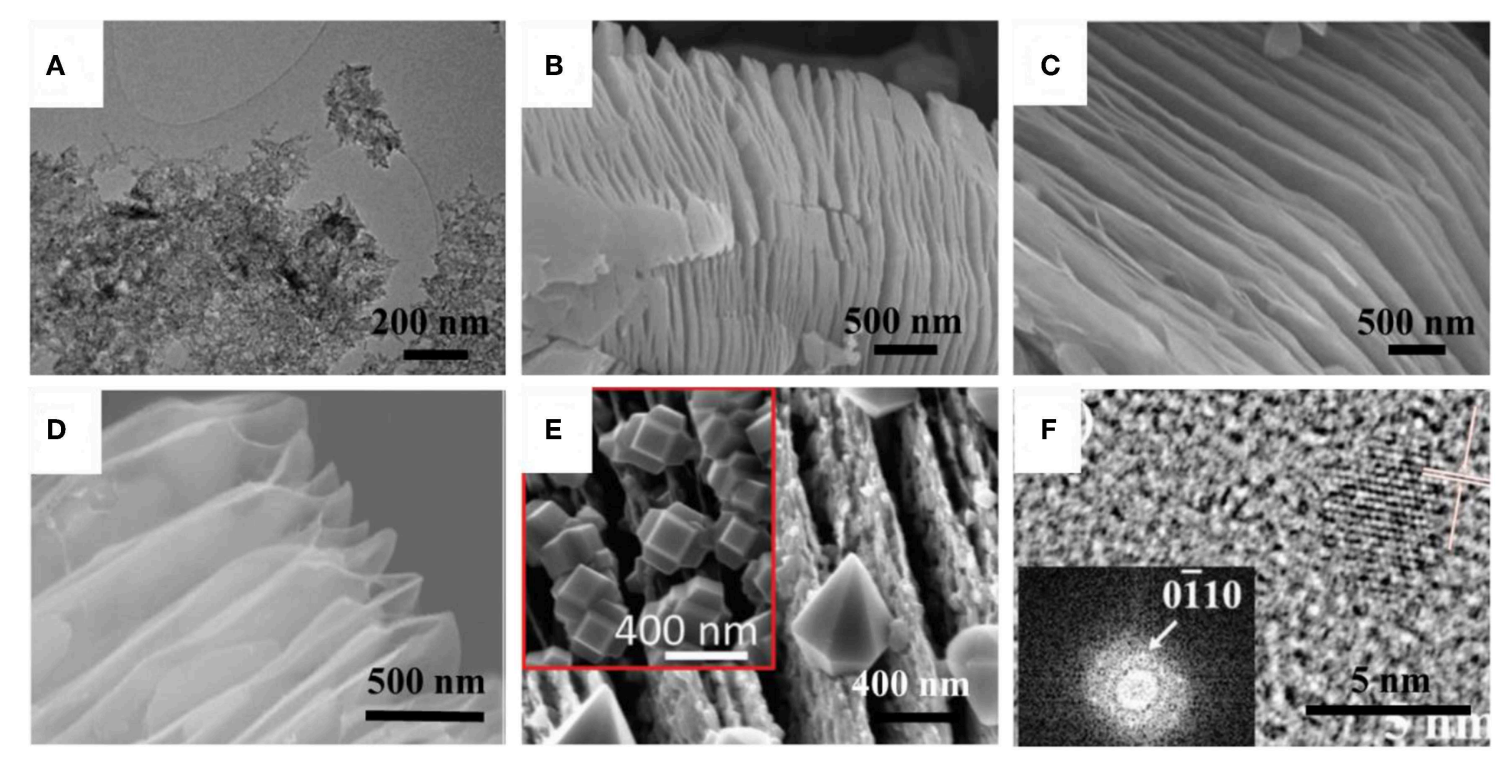

FIGURE 2 | (A) TEM images of MXene flakes of aged d-Ti $\mathrm{C}_{2} \mathrm{~T}_{x}$ solutions in Air@RT for 7 days. Reproduced from Zhang et al. (2017) with permission from American Chemical Society Wiley. SEM images of $\mathrm{Ti}_{3} \mathrm{C}_{2} \mathrm{~T}_{X}$ MXene (B) before annealing and (C) after annealing in Ar@800 $\mathrm{C}$ for $2 \mathrm{~h}$. Reproduced from Han et al. (2016) with permission from American Chemical Society. (D) SEM images of as-synthesized $\mathrm{C} / \mathrm{TiO}_{2}$ hybrids in $\mathrm{CO}_{2} @ 800^{\circ} \mathrm{C}$ for $1 \mathrm{~h}$. Reproduced from Han et al. (2017) with permission from American Chemical Society. (E) SEM image of $\mathrm{Ti}_{3} \mathrm{C}_{2} \mathrm{~T}_{x}$ flakes after oxidation in Air@1150 $\mathrm{C}$ for 30 s. Reproduced from Naguib et al. (2014) with permission from American Chemical Society. (F) HRTEM and FFT pattern of $\mathrm{Ti}_{3} \mathrm{C}_{2} \mathrm{~T}_{x}$ quantum dots at $150^{\circ} \mathrm{C}$. Reproduced from Xue et al. (2017b) with permission from Wiley. 
and atmosphere, and further according to whether the oxidation product contains MXenes, it can be divided into complete oxidation and incomplete oxidation. First, in the air atmosphere, most of the MXenes cannot be stably present, and the corresponding transition metal oxides will be formed, while the carbon layers are oxidized to $\mathrm{CO}_{2}$ or $\mathrm{CO}$. For example, the team of Zhou presented the different responses of $\mathrm{V}_{2} \mathrm{CT}_{\mathrm{X}}$ and $\mathrm{Ti}_{3} \mathrm{C}_{2} \mathrm{~T}_{\mathrm{X}}$ at selected temperatures (Wu et al., 2018). After a period of stability, within $150^{\circ} \mathrm{C}$, vanadium oxide began to form. At $1,000^{\circ} \mathrm{C}$, and the layered structure was utterly broken, and the phase was converted entirely to $\mathrm{V}_{2} \mathrm{O}_{5}$. As for the $\mathrm{Ti}_{3} \mathrm{C}_{2} \mathrm{~T}_{\mathrm{X}}$ MXene, within $200^{\circ} \mathrm{C}$, the layered structure remained unchanged, and only a small portion of the anatase was formed between the layers. At $1,000^{\circ} \mathrm{C}, \mathrm{Ti}_{3} \mathrm{C}_{2} \mathrm{~T}_{\mathrm{X}}$ was no longer present, leaving only a high temperature stable phase of rutile. Furthermore, with the protection of inert atmospheres, such as $\mathrm{Ar}, \mathrm{N}_{2}$, or $\mathrm{He}$, MXenes were able to retain their original layered structure over a range of temperatures, but still produced a small amount of oxide (Li et al., 2015; Rakhi et al., 2015; Han et al., 2016; Seredych et al., 2019; Xu et al., 2019). At the same time, the inert carbon layers were kept. When the temperature continued to rise, the crystal structure would change to a high-temperature stable type. For instance, Yin's group explored the thermal stability of $\mathrm{Ti}_{3} C_{2} T_{\mathrm{X}}$ within $800^{\circ} \mathrm{C}$ (Han et al., 2016). The layered structure was almost constant except that the sheet was thinned, and a small amount of invisible titanium dioxide was formed therein. Also, Yury's group revealed the non-negligible effect of surface terminations on the thermal stability of $\mathrm{Ti}_{3} C_{2} T_{\mathrm{X}}$, $\mathrm{Nb}_{2} C T_{\mathrm{X}}, \mathrm{Mo}_{2} C T_{\mathrm{X}}$ MXenes in the He atmosphere (Seredych et al., 2019). At $1,500^{\circ} \mathrm{C}, \mathrm{Ti}_{3} C_{2} T_{\mathrm{X}}$ was confirmed to converted to the TiC phase. As to the $\mathrm{NH}_{3}$ atmosphere, the oxidation behavior was similar to that of the inert atmosphere, but some nitrogen atoms would partially replace the carbon atoms in carbide MXenes to form N-doped MXenes (Wen et al., 2017; Bao et al., 2018). Wang's group managed the synthesis of $\mathrm{N}$-doped MXenes with 1.7-20.7 at\% surface $\mathrm{N}$ concentrations by annealing $\mathrm{Ti}_{3} C_{2} T_{\mathrm{X}}$ at $200-700^{\circ} \mathrm{C}$ in the $\mathrm{NH}_{3}$ atmosphere (Wen et al., 2017). Meanwhile, no signal of titanium oxide was detected, and original morphology stayed, similar to the results of the few-layered $\mathrm{Ti}_{3} C_{2} T_{\mathrm{X}}$.

Also, for a highly reducing atmosphere, such as $\mathrm{H}_{2}, \mathrm{H}_{2} / \mathrm{Ar}$, or $\mathrm{H}_{2} / \mathrm{N}_{2}$, the localized laminated structure can be well-maintained, and the amount of oxide formed is much smaller than that in the above conditions. Yin's group work showed that the $\mathrm{Ti}_{3} \mathrm{C}_{2} \mathrm{~T}_{\mathrm{X}}$ MXene flakes $\left(\mathrm{Ti}_{3} \mathrm{C}_{2} \mathrm{~T}_{\mathrm{X}}\right.$ and $\left.\mathrm{Ti}_{2} \mathrm{CT}_{\mathrm{X}}\right)$ had even become smoother after undergoing heat treatment at $500-800^{\circ} \mathrm{C}$ in $\mathrm{H}_{2} / \mathrm{Ar}$ condition, as displayed in Figures 2B,C (Li et al., 2017b; Xu et al., 2019). For the oxidizing atmosphere, such as $\mathrm{CO}_{2}$, the oxidation behavior of MXene should be divided into two types, as shown in Figures 2D,E (Naguib et al., 2014; Chen et al., 2015; Rakhi et al., 2015; Zhang et al., 2016; Han et al., 2017; Li et al., 2017a). At lower temperatures, both MXenes phase and layered structure can be reserved. Barsoum's group fabricated the $\mathrm{TiO}_{2} / \mathrm{Ti}_{2} C T_{\mathrm{X}} / \mathrm{C}$ and $\mathrm{Nb}_{2} \mathrm{O}_{5} / \mathrm{Nb}_{2} \mathrm{CT}_{\mathrm{X}}$ composites using the flash sinter process (Naguib et al., 2014). Besides, Yury's group synthesized the $\mathrm{Nb}_{2} \mathrm{O}_{5} / \mathrm{Nb}_{4} C_{3} \mathrm{~T}_{\mathrm{X}}$ (or $\mathrm{Nb}_{2} \mathrm{CT}_{\mathrm{X}}$ ) and $\mathrm{TiO}_{2} / \mathrm{Ti}_{3} \mathrm{C}_{2} \mathrm{~T}_{\mathrm{X}}$ composites by post-etch annealing at $850^{\circ} \mathrm{C}$ in flowing $\mathrm{CO}_{2}$ (Zhang et al., 2016). Remarkably, at higher temperatures, the oxidation behavior becomes completely different. The transition metal layers were oxidized while the middle carbon layer was wholly stripped, and thus MXene disappeared utterly, resulting in the pure $\mathrm{C} / \mathrm{TiO}_{2}$ composite with a highly ordered sandwich-like layered structure (Han et al., 2017; Li et al., 2017a).

\section{DEGRADATION UNDER HYDROTHERMAL CONDITION}

Unlike the conditions described above, the high temperature and pressure environment derived from the hydrothermal process, promote not only MXene phase transition, but also rich and varied structural evolution, especially in the presence of various regulators. Barsoum's group implemented the hydrothermal treatment at $150-250^{\circ} \mathrm{C}$ under $1-5 \mathrm{MPa}$ pressure and obtained $\mathrm{Ti}_{3} \mathrm{C}_{2} \mathrm{~T}_{\mathrm{X}} / \mathrm{TiO}_{2} / \mathrm{C}$ composites, which owned a similar microstructure to that obtained by thermal treatment in $\mathrm{CO}_{2}$ (Naguib et al., 2014). Also, Mei's group explored the layer-stacked $\mathrm{Ti}_{3} \mathrm{C}_{2} \mathrm{~T}_{\mathrm{X}} / \mathrm{TiO}_{2}$ phase via a similar process at $200^{\circ} \mathrm{C}$ (Tang et al., 2016). Moreover, Cao's group recorded the formation of spherical $\mathrm{TiO}_{2}$ on the surface of $\mathrm{Ti}_{3} \mathrm{C}_{2} \mathrm{~T}_{\mathrm{X}}$ at $180^{\circ} \mathrm{C}$ (Gao et al., 2015). But, in the alkalization environment, results changed significantly. As highlighted by Bao's group, after introducing $\mathrm{KOH}+\mathrm{H}_{2} \mathrm{O}_{2}$ and $\mathrm{NaOH}+\mathrm{H}_{2} \mathrm{O}_{2}$, the original accordionlike particles evolved into intertwined flexible nanobelts, and $\mathrm{Ti}_{3} \mathrm{C}_{2} \mathrm{~T}_{\mathrm{X}}$ MXenes were also totally converted into $\mathrm{K}_{2} \mathrm{Ti}_{4} \mathrm{O}_{9}$ and $\mathrm{NaTi}_{1.5} \mathrm{O}_{8.3}$, respectively (Dong et al., 2017). Furthermore, when the regulator changed to $\mathrm{CH}_{3} \mathrm{COONa} \cdot 3 \mathrm{H}_{2} \mathrm{O}+\mathrm{H}_{3} \mathrm{PO}_{4}+\mathrm{H}_{2} \mathrm{O}_{2}$, $\mathrm{Na}^{+}$, and $\mathrm{PO}_{3}^{2-}$ reacted with existed $\mathrm{TiO}_{2}$ that had been formed, to generate $\mathrm{NaTi}_{2}\left(\mathrm{PO}_{4}\right)_{3}$ at $160^{\circ} \mathrm{C}$ (Yang Q. et al., 2018). During the reaction, $\mathrm{TiO}_{2}$ acted as the seed layer to guide the uniform nucleation and growth of $\mathrm{NaTi}_{2}\left(\mathrm{PO}_{4}\right)_{3}$.

Moreover, hydrothermal is also an effortless facile way of synthesizing MXenes quantum dots. Zhi's group adopt $\mathrm{Ti}_{3} \mathrm{C}_{2} \mathrm{~T}_{\mathrm{X}}$ MXenes as the precursor to manufacture quantum dots with different size, and quantum yield was up to about $10 \%$ (Xue et al., 2017b). It is worth noting that the resulting quantum dots were monolayer and water soluble. Their size was tailored to the reaction temperature. The average lateral size reached about 2.9, 3.7, and $6.2 \mathrm{~nm}$, corresponding to the reaction temperature of 100,120 , and $150^{\circ} \mathrm{C}$, respectively, showing an apparent positive correlation. Unfortunately, with the increase of heat, the loss of $\mathrm{Ti}$ atoms on the surface of $\mathrm{Ti}_{3} \mathrm{C}_{2} \mathrm{~T}_{\mathrm{X}}$ quantum dots also deteriorated. At $150^{\circ} \mathrm{C}$, the crystallinity was inferior to the low-temperature products, and even a small number of carbon quantum dots were detected (Figure 2F). Besides, Xu's group designed $2 \mathrm{D} \mathrm{N}$-doped quantum dots based on $\mathrm{Ti}_{3} \mathrm{C}_{2} \mathrm{~T}_{\mathrm{X}}$ via the hydrothermal process combined with $\mathrm{HNO}_{3}$ pre-treatment (Xu Q. et al., 2018). Specifically, the precursor $\mathrm{Ti}_{3} \mathrm{C}_{2} \mathrm{~T}_{\mathrm{X}}$ was nitrified using nitric acid for $5 \mathrm{~h}$ at $100^{\circ} \mathrm{C}$ and then subjected to a hydrothermal step at $160^{\circ} \mathrm{C}$ for $2 \mathrm{~h}$, with the addition of $\mathrm{NaOH}$ and ethanediamine. XPS revealed that some nitrogen atoms and carbon atoms were chemically bonded, suggesting the successful nitridation of $\mathrm{Ti}_{3} \mathrm{C}_{2} \mathrm{~T}_{\mathrm{X}}$ quantum dots. The lateral size was concentrated at $3.4 \mathrm{~nm}$. The quantum dots yield of up to 
$18.7 \%$ in this work was sufficient to demonstrate the effectiveness of this proposed method.

\section{CONCLUSION}

In summary, the etching process and subsequent processing environment definitely have a significant impact on the phase composition and microstructure and the associated physical/chemical properties of MXenes. The increasingly mature synthesis methods lay the foundation for their largescale application. The controllable microstructure and rich surface chemistry are also primarily important to determine the properties of MXenes. At low temperatures, the dark condition and vacuum and inert atmosphere are effective ways to isolate moisture and oxygen and then prevent the oxidation behavior, especially for few-layered MXenes. At high temperatures, this oxidation behavior tends to occur and associated transition metal oxides are formed. The phase transition temperature and products usually depend on the composition of MXenes and atmosphere conditions. At hydrothermal condition that provides high temperature and pressure, more varied microstructural transformations even MXenes quantum dots can be obtained

\section{REFERENCES}

Ahmed, B., Anjum, D. H., Hedhili, M. N., Gogotsi, Y., and Alshareef, H. N. (2016). $\mathrm{H}_{2} \mathrm{O}_{2}$ assisted room temperature oxidation of $\mathrm{Ti}_{2} \mathrm{C}$ MXene for Li-ion battery anodes. iNanoscale 8, 7580-7587. doi: 10.1039/C6NR00002A

Anasori, B., Lukatskaya, M. R., and Gogotsi, Y. (2017). 2D metal carbides and nitrides (MXenes) for energy storage. Nat. Rev. Mater. 2:16098. doi: 10.1038/natrevmats.2016.98

Anasori, B., Shi, C., Moon, E. J., Xie, Y., Voigt, C. A., Kent, P. R., et al. (2016). Control of electronic properties of 2D carbides (MXenes) by manipulating their transition metal layers. Nanoscale Horizons 1, 227-234. doi: 10.1039/C5NH00125K

Anasori, B., Xie, Y., Beidaghi, M., Lu, J., Hosler, B. C., Hultman, L., et al. (2015). Two-dimensional, ordered, double transition metals carbides (MXenes). ACS Nano 9, 9507-9516. doi: 10.1021/acsnano.5b03591

Bao, W., Liu, L., Wang, C., Choi, S., Wang, D., and Wang, G. (2018). Facile synthesis of crumpled nitrogen-doped MXene nanosheets as a new sulfur host for lithium-sulfur batteries. Adv. Energy Mater. 8:1702485. doi: 10.1002/aenm.201870060

Byeon, A., Zhao, M.-Q., Ren, C. E., Halim, J., Kota, S., Urbankowski, P., et al. (2016). Two-dimensional titanium carbide MXene as a cathode material for hybrid magnesium/lithium-ion batteries. ACS Appl. Mater. Interfaces 9, 4296-4300. doi: 10.1021/acsami.6b04198

Chen, J., Chen, K., Tong, D., Huang, Y., Zhang, J., Xue, J., et al. (2015). $\mathrm{CO}_{2}$ and temperature dual responsive "Smart" MXene phases. Chem. Commun. 51, 314-317. doi: 10.1039/C4CC07220K

Dong, Y., Wu, Z. S., Zheng, S., Wang, X., Qin, J., Wang, S., et al. (2017). Ti ${ }_{3} \mathrm{C}_{2}$ MXene-derived sodium/potassium titanate nanoribbons for high-performance sodium/potassium ion batteries with enhanced capacities. ACS Nano 11, 4792-4800. doi: 10.1021/acsnano.7b01165

Er, D., Li, J., Naguib, M., Gogotsi, Y., and Shenoy, V. B. (2014). $\mathrm{Ti}_{3} \mathrm{C}_{2}$ MXene as a high capacity electrode material for metal ( $\mathrm{Li}, \mathrm{Na}, \mathrm{K}, \mathrm{Ca}$ ) ion batteries. ACS Appl. Mater. Interfaces 6, 11173-11179. doi: 10.1021/am $501144 \mathrm{q}$

Fashandi, H., Dahlqvist, M., Lu, J., Palisaitis, J., Simak, S. I., Abrikosov, I. A., et al. (2017). Synthesis of $\mathrm{Ti}_{3} \mathrm{AuC}_{2}, \mathrm{Ti}_{3} \mathrm{Au}_{2} \mathrm{C}_{2}$ and $\mathrm{Ti}_{3} \mathrm{IrC}_{2}$ by noble metal substitution reaction in $\mathrm{Ti}_{3} \mathrm{SiC}_{2}$ for high-temperature-stable ohmic contacts to SiC. Nat. Mater. 16:814. doi: 10.1038/nmat4896 except for the above phase transition by adjusting the additives with different $\mathrm{pH}$. Unique electronic and chemical properties are making MXenes stand out in many fields, in particular, energy storage. It is foreseeable that the wide variety of MXenes derivate available in different environments will offer considerable possibilities for future expansion. Therefore, while developing new MXenes, profoundly exploring their transformation behavior in extensive settings should be worthy and necessary.

\section{AUTHOR CONTRIBUTIONS}

$\mathrm{XL}$ and $\mathrm{ZH}$ wrote the manuscript. CZ supervised and communicated the manuscript.

\section{FUNDING}

This research was supported by GRF under Project N_CityU11305218. The work was also partially sponsored by the Science Technology and Innovation Committee of Shenzhen Municipality (the Grant No. JCYJ20170818103435068) and a grant from City University of Hong Kong (9667165).

Feng, A., Yu, Y., Jiang, F., Wang, Y., Mi, L., Yu, Y., et al. (2017). Fabrication and thermal stability of $\mathrm{NH}_{4} \mathrm{HF}_{2}$-etched $\mathrm{Ti}_{3} \mathrm{C}_{2}$ MXene. Ceramics Int. 43, 6322-6328. doi: 10.1016/j.ceramint.2017.02.039

Gao, Y., Wang, L., Zhou, A., Li, Z., Chen, J., Bala, H., et al. (2015). Hydrothermal synthesis of $\mathrm{TiO}_{2} / \mathrm{Ti}_{3} \mathrm{C}_{2}$ nanocomposites with enhanced photocatalytic activity. Mater. Lett. 150, 62-64. doi: 10.1016/j.matlet.2015.02.135

Ghidiu, M., Lukatskaya, M. R., Zhao, M.-Q., Gogotsi, Y., and Barsoum, M. W. (2014a). Conductive two-dimensional titanium carbide 'clay'with high volumetric capacitance. Nature 516:78. doi: 10.1038/nature13970

Ghidiu, M., Naguib, M., Shi, C., Mashtalir, O., Pan, L., Zhang, B., et al. (2014b). Synthesis and characterization of two-dimensional $\mathrm{Nb}_{4} \mathrm{C}_{3}$ (MXene). Chem. Commu. 50, 9517-9520. doi: 10.1039/C4CC03366C

Halim, J., Lukatskaya, M. R., Cook, K. M., Lu, J., Smith, C. R., Näslund, L.-Å., et al. (2014). Transparent conductive two-dimensional titanium carbide epitaxial thin films. Chem. Mater. 26, 2374-2381. doi: 10.1021/cm500641a

Han, M., Yin, X., Li, X., Anasori, B., Zhang, L., Cheng, L., et al. (2017). Laminated and two-dimensional carbon-supported microwave absorbers derived from MXenes. ACS Appl. Mater. Interfaces 9, 20038-20045. doi: 10.1021/acsami.7b04602

Han, M., Yin, X., Wu, H., Hou, Z., Song, C., Li, X., et al. (2016). $\mathrm{Ti}_{3} \mathrm{C}_{2}$ MXenes with modified surface for high-performance electromagnetic absorption and shielding in the X-Band. ACS Appl. Mater. Interfaces 8, 21011-21019. doi: 10.1021/acsami.6b06455

Hong Ng, V. M., Huang, H., Zhou, K., Lee, P. S., Que, W., Xu, J. Z., et al. (2017). Recent progress in layered transition metal carbides and/or nitrides (MXenes) and their composites: synthesis and applications. J. Mater. Chem. A 5, 3039-3068. doi: 10.1039/C6TA06772G

Huang, Z., Hou, H., Wang, C., Li, S., Zhang, Y., and Ji, X. (2017a). Molybdenum phosphide: a conversion-type anode for ultralong-life sodium-ion batteries. Chem. Mater. 29, 7313-7322. doi: 10.1021/acs.chemmater.7b02193

Huang, Z., Hou, H., Zhang, Y., Wang, C., Qiu, X., and Ji, X. (2017b). Layer-tunable phosphorene modulated by the cation insertion rate as a sodium-storage anode. Adv. Mater. 29:1702372. doi: 10.1002/adma.201702372

Huang, Z., Hou, H., Zou, G., Chen, J., Zhang, Y., Liao, H., et al. (2016). 3D porous carbon encapsulated $\mathrm{SnO}_{2}$ nanocomposite for ultrastable sodium ion batteries. Electrochim. Acta 214, 156-164. doi: 10.1016/j.electacta.2016.08.040

Huang, Z., Li, X., Yang, Q., Ma, L., Mo, F., Liang, G., et al. (2019). $\mathrm{Ni}_{3} \mathrm{~S}_{2} / \mathrm{Ni}$ nanosheets arrays for high-performance flexible zinc hybrid battery with 
evident two-stage charge and discharge process. J. Mater. Chem. A 7, 18915-18924. doi: 10.1039/C9TA06337D

Kang, L., Cui, M., Jiang, F., Gao, Y., Luo, H., Liu, J., et al. (2018). Nanoporous $\mathrm{CaCO}_{3}$ coatings enabled uniform zn stripping/plating for longlife zinc rechargeable aqueous batteries. Adv. Energy Mater. 8:1801090. doi: $10.1002 /$ aenm.201801090

Khazaei, M., Ranjbar, A., Esfarjani, K., Bogdanovski, D., Dronskowski, R., and Yunoki, S. (2018). Insights into exfoliation possibility of MAX phases to MXenes. Phys. Chem. Chem. Phys. 20, 8579-8592. doi: 10.1039/C7CP08645H

Kim, S. J., Naguib, M., Zhao, M., Zhang, C., Jung, H.-T., Barsoum, M. W., et al. (2015). High mass loading, binder-free MXene anodes for high areal capacity Li-ion batteries. Electrochim. Acta 163, 246-251. doi: $10.1016 /$ j.electacta.2015.02.132

Li, H., Han, C., Huang, Y., Huang, Y., Zhu, M., Pei, Z., et al. (2018). An extremely safe and wearable solid-state zinc ion battery based on a hierarchical structured polymer electrolyte. Energy Environ. Sci. 11, 941-951. doi: 10.1039/C7EE03232C

Li, H., Ma, L., Han, C., Wang, Z., Liu, Z., Tang, Z., et al. (2019). Advanced rechargeable zinc-based batteries: recent progress and future perspectives. Nano Energy 62, 550-587. doi: 10.1016/j.nanoen.2019.05.059

Li, M., Lu, J., Luo, K., Li, Y., Chang, K., Chen, K., et al. (2019). An element replacement approach by reaction with lewis acidic molten salts to synthesize nanolaminated max phases and MXenes. J. Am. Chem. Soc. 141, 4730-4737. doi: $10.1021 /$ jacs.9b00574

Li, T., Yao, L., Liu, Q., Gu, J., Luo, R., Li, J., et al. (2018). Fluorine-free synthesis of high-purity $\mathrm{Ti}_{3} \mathrm{C}_{2} \mathrm{~T}_{\mathrm{X}}(\mathrm{T}=\mathrm{OH}, \mathrm{O})$ via alkali treatment. Angewan. Chem. Int. Ed. 57, 6115-6119. doi: 10.1002/anie.201800887

Li, X., Yin, X., Han, M., Song, C., Sun, X., Xu, H., et al. (2017a). A controllable heterogeneous structure and electromagnetic wave absorption properties of $\mathrm{Ti}_{2} \mathrm{CT}_{\mathrm{x}}$ MXene. J. Mater. Chem. C 5, 7621-7628. doi: 10.1039/C7TC01991B

Li, X., Yin, X., Han, M., Song, C., Xu, H., Hou, Z., et al. (2017b). $\mathrm{Ti}_{3} \mathrm{C}_{2}$ MXenes modified with in situ grown carbon nanotubes for enhanced electromagnetic wave absorption properties. J. Mater. Chem. C 5, 4068-4074. doi: 10.1039/C6TC05226F

Li, Z., Wang, L., Sun, D., Zhang, Y., Liu, B., Hu, Q., et al. (2015). Synthesis and thermal stability of two-dimensional carbide MXene $\mathrm{Ti}_{3} \mathrm{C}_{2}$. Mater. Sci. Eng. B 191, 33-40. doi: 10.1016/j.mseb.2014.10.009

Liang, G., Liu, Z., Mo, F., Tang, Z., Li, H., Wang, Z., et al. (2018). Self-healable electroluminescent devices. Light Sci. Appl. 7:102. doi: 10.1038/s41377-018-0096-8

Liang, G., Mo, F., Li, H., Tang, Z., Liu, Z., Wang, D., et al. (2019). A universal principle to design reversible aqueous batteries based on deposition-dissolution mechanism. Adv. Energy Mater. 9:1901838. doi: 10.1002/aenm.201901838

Liang, X., Rangom, Y., Kwok, C. Y., Pang, Q., and Nazar, L. F. (2017). Interwoven MXene nanosheet/carbon-nanotube composites as Li-S cathode hosts. Adv. Mater. 29:1603040. doi: 10.1002/adma.201603040

Liu, R., Cao, W., Han, D., Mo, Y., Zeng, H., Yang, H., et al. (2019). Nitrogen-doped Nb2CTx MXene as anode materials for lithium ion batteries. J. Alloys Comp. 793, 505-511. doi: 10.1016/j.jallcom.2019.03.209

Liu, Z., Liang, G., Zhan, Y., Li, H., Wang, Z., Ma, L., et al. (2019a). A soft yet device-level dynamically super-tough supercapacitor enabled by an energydissipative dual-crosslinked hydrogel electrolyte. Nano Energy 58, 732-742. doi: 10.1016/j.nanoen.2019.01.087

Liu, Z., Wang, D., Tang, Z., Liang, G., Yang, Q., Li, H., et al. (2019b). A mechanically durable and device-level tough $\mathrm{Zn}-\mathrm{MnO}_{2}$ battery with high flexibility. Energy Stor. Mater. 23, 636-645. doi: 10.1016/j.ensm.2019.03.007

Lukatskaya, M. R., Mashtalir, O., Ren, C. E., Dall'Agnese, Y., Rozier, P., Taberna, P. L., et al. (2013). Cation intercalation and high volumetric capacitance of two-dimensional titanium carbide. Science 341, 1502-1505. doi: $10.1126 /$ science. 1241488

Luo, S., Xie, L., Han, F., Wei, W., Huang, Y., Zhang, H., et al. (2019). Nanoscale parallel circuitry based on interpenetrating conductive assembly for flexible and high-power zinc ion battery. Adv. Funct. Mater. 29:1901336. doi: 10.1002/adfm.201901336

Ma, L., Zhao, Y., Ji, X., Zeng, J., Yang, Q., Guo, Y., et al. (2019). A usage scenario independent "air chargeable" flexible zinc ion energy storage device. Adv. Energy Mater. 9:1900509. doi: 10.1002/aenm.201900509
Mashtalir, O., Cook, K. M., Mochalin, V., Crowe, M., Barsoum, M. W., and Gogotsi, Y. (2014). Dye adsorption and decomposition on two-dimensional titanium carbide in aqueous media. J. Mater. Chem. A 2, 14334-14338. doi: $10.1039 /$ C4TA02638A

Mashtalir, O., Lukatskaya, M. R., Zhao, M. Q., Barsoum, M. W., and Gogotsi, Y. (2015). Amine-assisted delamination of $\mathrm{Nb}_{2} \mathrm{C}$ MXene for Li-ion energy storage devices. Adv. Mater. 27, 3501-3506. doi: 10.1002/adma.201500604

Mashtalir, O., Naguib, M., Mochalin, V. N., Dall'Agnese, Y., Heon, M., Barsoum, M. W., et al. (2013). Intercalation and delamination of layered carbides and carbonitrides. Nat. Commun. 4:1716. doi: 10.1038/ncomms2664

Mian, L., You-Bing, L., Kan, L., Lu, J., Eklund, P., Persson, P. O., et al. (2019). Synthesis of novel MAX phase $\mathrm{Ti}_{3} \mathrm{ZnC}_{2}$ via A-site-element-substitution approach. J. Inorg. Mater. 34, 60-64. doi: 10.15541/jim20180377

Mišković-Stanković, V., Jevremović, I., Jung, I., and Rhee, K. (2014). Electrochemical study of corrosion behavior of graphene coatings on copper and aluminum in a chloride solution. Carbon 75, 335-344. doi: 10.1016/j.carbon.2014.04.012

Mo, F., Liang, G., Huang, Z., Li, H., Wang, D., and Zhi, C. (2019). An overview of fiber-shaped batteries with a focus on multifunctionality, scalability, and technical difficulties. Adv. Mater. 31:1902151. doi: 10.1002/adma.201902151

Naguib, M., Halim, J., Lu, J., Cook, K. M., Hultman, L., Gogotsi, Y., et al. (2013). New two-dimensional niobium and vanadium carbides as promising materials for Li-ion batteries. J. Am. Chem. Soc. 135, 15966-15969. doi: $10.1021 /$ ja $405735 \mathrm{~d}$

Naguib, M., Kurtoglu, M., Presser, V., Lu, J., Niu, J., Heon, M., et al. (2011). Two-dimensional nanocrystals: two-dimensional nanocrystals produced by exfoliation of $\mathrm{Ti}_{3} \mathrm{AlC}_{2}$ (Adv. Mater. 37/2011). Adv. Mater. 23:4207. doi: 10.1002/adma.201190147

Naguib, M., Mashtalir, O., Lukatskaya, M. R., Dyatkin, B., Zhang, C., Presser, V., et al. (2014). One-step synthesis of nanocrystalline transition metal oxides on thin sheets of disordered graphitic carbon by oxidation of MXenes. Chem. Commun. 50, 7420-7423. doi: 10.1039/C4CC01646G

Naguib, M., Unocic, R. R., Armstrong, B. L., and Nanda, J. (2015). Largescale delamination of multi-layers transition metal carbides and carbonitrides "MXenes". Dalton Trans. 44, 9353-9358. doi: 10.1039/C5DT01247C

Pang, S. Y., Wong, Y. T., Yuan, S., Liu, Y., Tsang, M. K., Yang, Z., et al. (2019). A universal strategy for HF-free facile and rapid synthesis of $2 \mathrm{D}$ MXenes as multifunctional energy materials. J. Am. Chem. Soc. 141, 9610-9616. doi: 10.1021/jacs.9b02578

Rakhi, R. B., Ahmed, B., Hedhili, M. N., Anjum, D. H., and Alshareef, H. N. (2015). Effect of postetch annealing gas composition on the structural and electrochemical properties of $\mathrm{Ti}_{2} \mathrm{CTx}$ MXene electrodes for supercapacitor applications. Chem. Mater. 27, 5314-5323. doi: 10.1021/acs.chemmater.5b01623

Seredych, M., Shuck, C. E., Pinto, D., Alhabeb, M., Precetti, E., Deysher, G., et al. (2019). High-temperature behavior and surface chemistry of carbide MXenes studied by thermal analysis. Chem. Mater. 31, 3324-3332. doi: 10.1021/acs.chemmater.9b00397

Srivastava, P., Mishra, A., Mizuseki, H., Lee, K.-R., and Singh, A. K. (2016). Mechanistic insight into the chemical exfoliation and functionalization of $\mathrm{Ti}_{3} \mathrm{C}_{2}$ MXene. ACS Appl. Mater. Interfaces 8, 24256-24264. doi: $10.1021 /$ acsami.6b08413

Tang, H., Li, W., Pan, L., Tu, K., Du, F., Qiu, T., et al. (2019). A robust, freestanding MXene-sulfur conductive paper for long-lifetime Li-S batteries. Adv. Func. Mater. 29:1901907. doi: 10.1002/adfm.201901907

Tang, H., Zhuang, S., Bao, Z., Lao, C., and Mei, Y. (2016). Two-step oxidation of Mxene in the synthesis of layer-stacked anatase titania with enhanced lithium-storage performance. ChemElectroChem 3, 871-876. doi: $10.1002 /$ celc.201600078

Tran, M. H., Schäfer, T., Shahraei, A., Dürrschnabel, M., Molina-Luna, L., Kramm, U. I., et al. (2018). Adding a new member to the MXene family: synthesis, structure, and electrocatalytic activity for the hydrogen evolution reaction of $\mathrm{V}_{4} C_{3} T_{\mathrm{x}}$. ACS Appl. Energy Mater. 1, 3908-3914. doi: 10.1021/acsaem.8b00652

Urbankowski, P., Anasori, B., Makaryan, T., Er, D., Kota, S., Walsh, P. L., et al. (2016). Synthesis of two-dimensional titanium nitride $\mathrm{Ti}_{4} N_{3}$ (MXene). Nanoscale 8, 11385-11391. doi: 10.1039/C6NR02253G

VahidMohammadi, A., Hadjikhani, A., Shahbazmohamadi, S., and Beidaghi, M. (2017). Two-dimensional vanadium carbide (MXene) as a high-capacity 
cathode material for rechargeable aluminum batteries. ACS Nano 11, 11135-11144. doi: 10.1021/acsnano.7b05350

Wang, B., Zhou, A., Hu, Q., and Wang, L. (2017). Synthesis and oxidation resistance of $\mathrm{V}_{2} \mathrm{AlC}$ powders by molten salt method. Int. J. Appl. Ceramic Technol. 14, 873-879. doi: 10.1111/ijac.12723

Wang, D., Li, H., Liu, Z., Tang, Z., Liang, G., Mo, F., et al. (2018). A nanofibrillated cellulose/polyacrylamide electrolyte-based flexible and sewable high-performance $\mathrm{Zn}-\mathrm{MnO}_{2}$ battery with superior shear resistance. Small 14:1803978. doi: 10.1002/smll.201803978

Wang, L., Zhang, H., Wang, B., Shen, C., Zhang, C., Hu, Q., et al. (2016). Synthesis and electrochemical performance of $\mathrm{Ti}_{3} \mathrm{C}_{2} \mathrm{~T}_{\mathrm{x}}$ with hydrothermal process. Electr. Mater. Lett. 12, 702-710. doi: 10.1007/s13391-016-6088-z

Wang, X., Garnero, C., Rochard, G., Magne, D., Morisset, S., Hurand, S., et al. (2017). A new etching environment $\left(\mathrm{FeF}_{3} / \mathrm{HCl}\right)$ for the synthesis of two-dimensional titanium carbide MXenes: a route towards selective reactivity vs. water. J. Mater. Chem. A 5, 22012-22023. doi: 10.1039/C7TA 01082F

Wen, Y., Rufford, T. E., Chen, X., Li, N., Lyu, M., Dai, L., et al. (2017). Nitrogendoped $\mathrm{Ti}_{3} \mathrm{C}_{2} \mathrm{~T}_{\mathrm{X}}$ MXene electrodes for high-performance supercapacitors. Nano Energy 38, 368-376. doi: 10.1016/j.nanoen.2017.06.009

Wu, M., Wang, B., Hu, Q., Wang, L., and Zhou, A. (2018). The synthesis process and thermal stability of $\mathrm{V}(2) \mathrm{C}$ MXene. Materials 11:2112. doi: $10.3390 /$ ma11112112

Xie, Y., Naguib, M., Mochalin, V. N., Barsoum, M. W., Gogotsi, Y., Yu, X., et al. (2014). Role of surface structure on Li-ion energy storage capacity of two-dimensional transition-metal carbides. J. Am. Chem. Soc. 136, 6385-6394. doi: $10.1021 / \mathrm{ja} 501520 \mathrm{~b}$

Xu, H., Yin, X., Li, X., Li, M., Zhang, L., and Cheng, L. (2019). Thermal stability and dielectric properties of $2 \mathrm{D} \mathrm{Ti}_{2} \mathrm{C}$ MXenes via annealing under a gas mixture of $\mathrm{Ar}$ and $\mathrm{H}_{2}$ atmosphere. Func. Compo. Struct. 1:015002. doi: $10.1088 / 2631-6331 / \mathrm{ab} 0 \mathrm{c} 82$

Xu, M., Lei, S., Qi, J., Dou, Q., Liu, L., Lu, Y., et al. (2018). Opening magnesium storage capability of two-dimensional MXene by intercalation of cationic surfactant. ACS Nano 12, 3733-3740. doi: 10.1021/acsnano.8b00959

Xu, Q., Ding, L., Wen, Y., Yang, W., Zhou, H., Chen, X., et al. (2018). High photoluminescence quantum yield of $18.7 \%$ by using nitrogendoped $\mathrm{Ti}_{3} \mathrm{C}_{2}$ MXene quantum dots. J. Mater. Chem. C 6, 6360-6369. doi: $10.1039 / \mathrm{C} 8 \mathrm{TC} 02156 \mathrm{~B}$

Xuan, J., Wang, Z., Chen, Y., Liang, D., Cheng, L., Yang, X., et al. (2016). Organic-base-driven intercalation and delamination for the production of functionalized titanium carbide nanosheets with superior photothermal therapeutic performance. Angewan. Chem. Int. Ed. 55, 14569-14574. doi: 10.1002/anie.201606643

Xue, Q., Pei, Z., Huang, Y., Zhu, M., Tang, Z., Li, H., et al. (2017a). $\mathrm{Mn}_{3} \mathrm{O}_{4}$ nanoparticles on layer-structured $\mathrm{Ti}_{3} \mathrm{C}_{2}$ MXene towards the oxygen reduction reaction and zinc-air batteries. J. Mater. Chem. A 5, 20818-20823. doi: $10.1039 / \mathrm{C} 7 \mathrm{TA} 04532 \mathrm{H}$

Xue, Q., Zhang, H., Zhu, M., Pei, Z., Li, H., Wang, Z., et al. (2017b). Photoluminescent $\mathrm{Ti}_{3} \mathrm{C}_{2}$ MXene quantum dots for multicolor cellular imaging. Adv. Mater. 29:1604847. doi: 10.1002/adma.201604847
Yang, J., Naguib, M., Ghidiu, M., Pan, L. M., Gu, J., Nanda, J., et al. (2016). Twodimensional Nb-based $\mathrm{M}_{4} \mathrm{C}_{3}$ solid solutions (MXenes). J. Am. Ceramic Soc. 99, 660-666. doi: 10.1111/jace.13922

Yang, Q., Huang, Z., Li, X., Liu, Z., Li, H., Liang, G., et al. (2019a). A wholly degradable, rechargeable $\mathrm{Zn}-\mathrm{Ti}_{3} \mathrm{C}_{2}$ MXene capacitor with superior anti-selfdischarge function. ACS Nano 13, 8275-8283. doi: 10.1021/acsnano.9b03650

Yang, Q., Jiao, T., Li, M., Li, Y., Ma, L., Mo, F., et al. (2018). In situ formation of $\mathrm{NaTi}_{2}\left(\mathrm{PO}_{4}\right)_{3}$ cubes on $\mathrm{Ti}_{3} \mathrm{C}_{2}$ MXene for dual-mode sodium storage. J. Mater. Chem. A 6, 18525-18532. doi: 10.1039/C8TA06995F

Yang, Q., Mo, F., Liu, Z., Ma, L., Li, X., Fang, D., et al. (2019b). Activating Ccoordinated iron of iron hexacyanoferrate for $\mathrm{Zn}$ hybrid-ion batteries with 10000-Cycle lifespan and superior rate capability. Adv. Mater. 31:e1901521. doi: 10.1002/adma.201901521

Yang, S., Zhang, P., Wang, F., Ricciardulli, A. G., Lohe, M. R., Blom, P. W. M., et al. (2018). Fluoride-free synthesis of two-dimensional titanium carbide (MXene) using a binary aqueous system. Angew. Chem. Int. Ed. 57, 15491-15495. doi: 10.1002/anie.201809662

Yu, H., Wang, Y., Jing, Y., Ma, J., Du, C. F., and Yan, Q. (2019). Surface modified MXene-based nanocomposites for electrochemical energy conversion and storage. Small 15:e1901503. doi: 10.1002/smll.201901503

Zhang, C., Kim, S. J., Ghidiu, M., Zhao, M. Q., Barsoum, M. W., Nicolosi, V., et al. (2016). Layered orthorhombic $\mathrm{Nb}_{2} \mathrm{O}_{5} @ \mathrm{Nb}_{4} \mathrm{C}_{3} \mathrm{~T}_{\mathrm{x}}$ and $\mathrm{TiO}_{2} @ \mathrm{Ti}_{3} \mathrm{C}_{2} \mathrm{~T}_{\mathrm{x}}$ hierarchical composites for high performance Li-ion batteries. Adv. Funct. Mater. 26, 4143-4151. doi: 10.1002/adfm.201600682

Zhang, C. J., Pinilla, S., McEvoy, N., Cullen, C. P., Anasori, B., Long, E., et al. (2017). Oxidation stability of colloidal two-dimensional titanium carbides (MXenes). Chem. Mater. 29, 4848-4856. doi: 10.1021/acs.chemmater.7b00745

Zhao, Y., Ma, L., Zhu, Y., Qin, P., Li, H., Mo, F., et al. (2019). Inhibiting grain pulverization and sulfur dissolution of bismuth sulfide by ionic liquid enhanced poly (3,4-ethylenedioxythiophene): poly (styrenesulfonate) for high-performance zinc-ion batteries. ACS Nano 13, 7270-7280. doi: $10.1021 /$ acsnano.9b02986

Zhou, J., Zha, X., Chen, F. Y., Ye, Q., Eklund, P., Du, S., et al. (2016), A two-dimensional zirconium carbide by selective etching of $\mathrm{Al}_{3} \mathrm{C}_{3}$ from nanolaminated $\mathrm{Zr}_{3} \mathrm{Al}_{3} \mathrm{C}_{5}$. Angew. Chem. Int. Ed. 55, 5008-5013. doi: 10.1002/anie.201510432

Zhu, M., Wang, Z., Li, H., Xiong, Y., Liu, Z., Tang, Z., et al. (2018). Lightpermeable, photoluminescent microbatteries embedded in the color filter of a screen. Energy Environ. Sci. 11, 2414-2422. doi: 10.1039/C8EE00590G

Conflict of Interest: The authors declare that the research was conducted in the absence of any commercial or financial relationships that could be construed as a potential conflict of interest.

Copyright $\odot 2019 \mathrm{Li}$, Huang and Zhi. This is an open-access article distributed under the terms of the Creative Commons Attribution License (CC BY). The use, distribution or reproduction in other forums is permitted, provided the original author(s) and the copyright owner(s) are credited and that the original publication in this journal is cited, in accordance with accepted academic practice. No use, distribution or reproduction is permitted which does not comply with these terms. 